\title{
Analysis of Aerodynamics Urban Electric Car Using Computational Fluid Dynamics
}

\author{
Didi Kusaeri ${ }^{1}$, MSK. Tony Suryo Utomo ${ }^{2}$ \\ \{didi.kusaeri@yahoo.com¹,msktonysu@yahoo.co.id ${ }^{2}$ \} \\ ${ }^{1,2}$ Mechanical Engineering, Diponegoro University Semarang, Indonesia
}

\begin{abstract}
This research is done by making electric car/Urban Electric Car with aerodynamic design. The purpose of this study is also often done. Because to the consumption of energy/fuel. The simulation is performed using Computational Fluid Dinamic. The turbulence method used $k-\varepsilon$ and its discretization method Second Order Upwind. Using variations of speed $15 \mathrm{~km} / \mathrm{h}, 30 \mathrm{~km} / \mathrm{h}, 45 \mathrm{~km} / \mathrm{h}$ and $60 \mathrm{~km} / \mathrm{h} \mathrm{from}$ simulation data performed the same result for four different speed variations, that is 0,4 . With the result also produce picture of the same airflow display at each speed. In the future there is expected to study the urban electric car by modifying existing car body parts, such as making more streamline on the front, rounded corner on the car and add a spoiler on the back of the car.
\end{abstract}

Keywords: Aerodynamics, Urban Electric Car, Computational Fluid Dynamics, Coefficient Drag

\section{Introduction}

The development of the automotive industry is progressing. This progress is characterized by the multitude of different brands of motor vehicles with each type of engine. This is very counterproductive with oil reserves in Indonesia as well as in an increasingly scarce world. To overcome the impact caused by the scarcity of oil availability, automotive/university manufacturers are deemed necessary to conduct research/research on alternative energy, for example electrically powered vehicles. It should also be supported with a model/type of car shape that can reduce the obstacles when driving that causes the impact of air impacts fuel consumption. Therefore it is very important in designing a car body, one aspect of aerodynamics. Such as the design of Ahmed Body which describes the fluid flow structure of the car, with the rounded front end shape, the middle part of the length and the end of the box with some angle of slope, which is considered effective to reduce drag coefficient (Thacher, 2012).

In the theory of aerodynamic forces, an object moving within a fluid medium or vice versa, will experience the forces at work. Similarly, motor vehicles moving through the air media, in addition to being influenced by the interaction between the car and the road/ground, then the vehicle will also experience aerodynamic styles. The main cause of the emergence of aerodynamic forces in the vehicle that is, firstly the distribution of pressure on the body surface of the vehicle that will work in the normal direction on the surface of the vehicle. Secondly, there is a shear stress distribution on the body surface of the vehicle that will work in the tangential direction of the vehicle surface. When the pressure and voltage distribution is integrated, it will be created by what is called aerodynamic lift (lift force) and drag force force (Drag Force) (Herminarto, 2004). 


\section{Research Purposes}

The aerodynamic obstacles that occur in the vehicle speed affect the vehicle fuel consumption. Reducing aerodynamic drag offers a solution to improve fuel efficiency and thus shape optimization becomes an essential part of the overall vehicle design process (Hasan Rakibul, et al, 2014). This study analyzes the aerodynamic drag force from the fluid flow pressure on the car body (Urban Electric Car) using the Computational Fluid Dinamic simulation, as an energy-efficient future car sample. The purpose of this research is to know the value of drag coefficient on urban electric car at speed $15 \mathrm{~km} / \mathrm{h}, 30 \mathrm{~km} / \mathrm{h}, 45 \mathrm{~km} / \mathrm{h}$ and 60 $\mathrm{km} / \mathrm{hour}$.

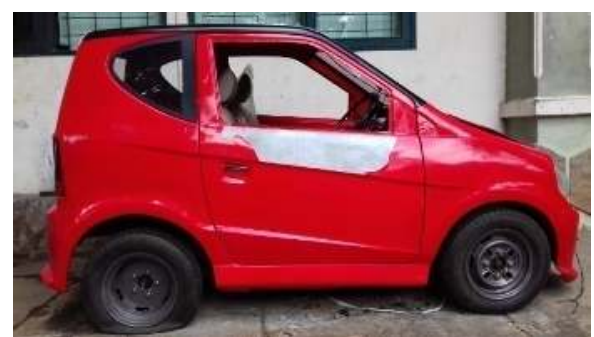

Fig. 1. Urban Electric Car.

\section{Research Methodology}

\subsection{Flow Chart}

Flow chart of this research as follows: 


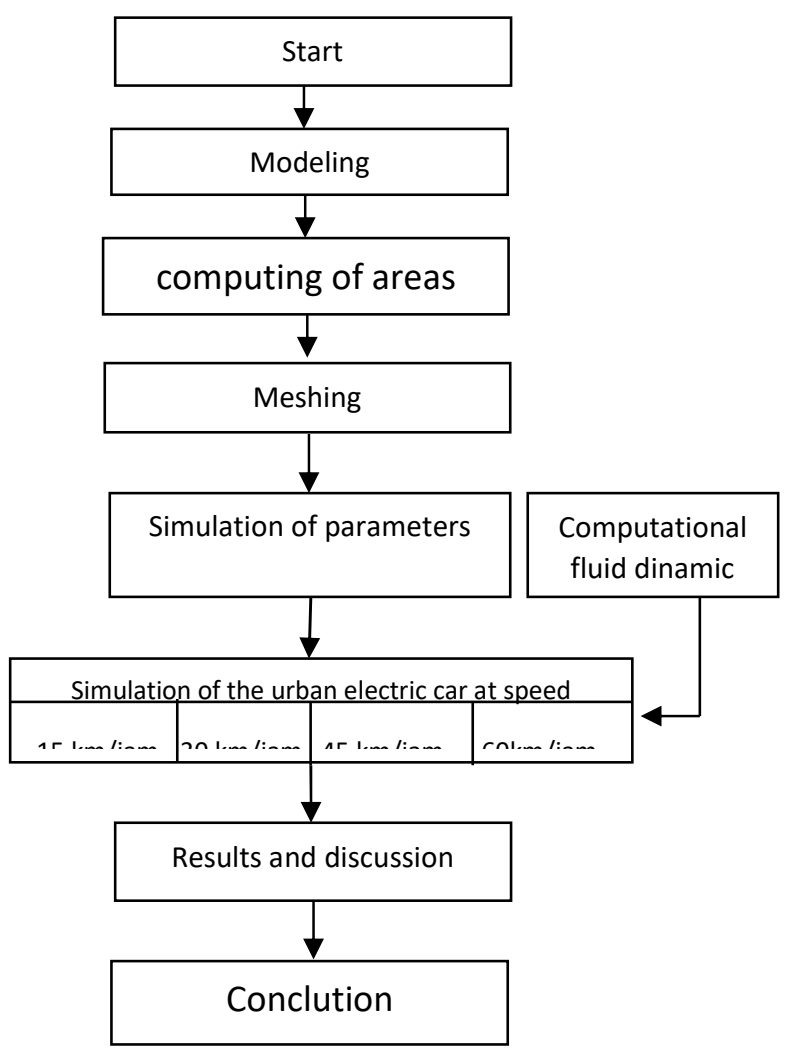

Fig. 2. Flow chart.

\subsection{Simulation Validation of Turbulent Methods}

In performing the simulation process, it is important to know the simulation done is correct or not is to do the validation of the experimental results or simulations that have been done before. In this simulation process validation is done by knowing the point of reattachment of backward-facing step phenomenon. The phenomenon of separation in the backward-facing step also occurs in the moving car, so it needs to be validated with the simulation results on the backward-facing step to determine the most appropriate turbulent model in determining the reattachment point. The flow on the backward-facing step produces a reverse circulation zone that is the occurrence of flow separation and forming a vortex. Figure 3 illustrates a backward-facing step scheme on turbulent flow. 


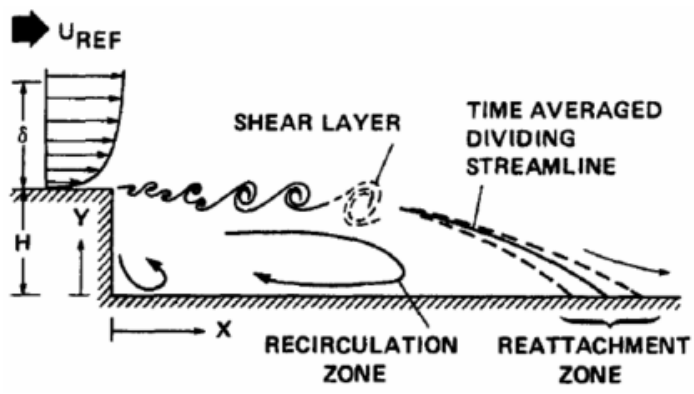

Fig. 3. Schematic of backward-facing step turbulent flow.

The part of the stream that separates the flow of circulation and flow through the midline of the channel is called the dividing streamline. The streamlined dividing attached to the wall is called the reattachment point, ie the flow moves down until it reaches a state of equilibrium and no backflow occurs. Table 1 illustrates the comparison of reattachment points of the simulations performed on each type of turbulent model with the distance of the reattachment point that has been done in the previous simulation of the literature. It can be seen that using the $\mathrm{k}-\varepsilon$ realizable turbulent method the distance of the reattachment point is obtained, which is closest to the simulation result from the literature with a difference of less than $5 \%$ ((Jongebled, 2008).

Table 1. Reattachment Point Distance from Model k- $\varepsilon$.

\begin{tabular}{lcccc}
\hline No & $\begin{array}{l}\text { turbulent } \\
\text { model k- } \varepsilon\end{array}$ & $\begin{array}{l}\text { Distance of } \\
\text { reattachment } \\
\text { point from } \\
\text { simulation } \\
(\mathrm{m})\end{array}$ & $\begin{array}{l}\text { Distance of } \\
\text { reattachment } \\
\text { point from } \\
\text { literature } \\
(\mathrm{m})\end{array}$ & $\begin{array}{l}\text { Error } \\
(\%)\end{array}$ \\
\hline 1 & Standard & 27 & 33,32 & 18,97 \\
\hline 2 & RNG & 29 & 33,32 & 12,9 \\
\hline 3 & Realizable & 32 & 33,32 & 3,96 \\
\hline
\end{tabular}

\subsection{Model Creation}

The first step is to create a model using Computer aided desigh software. Model making refers to the actual vehicle model. However, modeling is a bit of an experiment, which is intended to better understand the flow characteristics of the vehicle (Vino, 2005). 


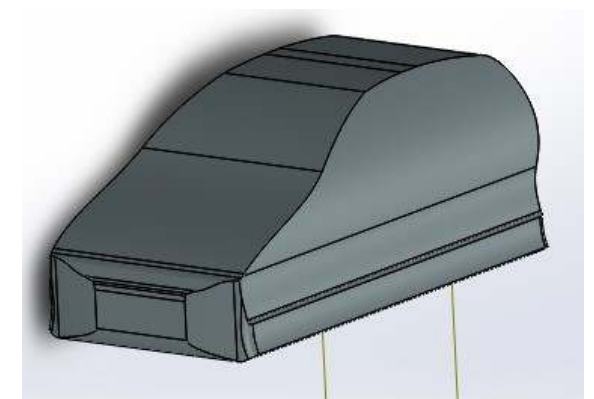

Fig. 4. Urban Electric Car Modeling.

Table 2. Urban Electric Car Specifications.

\begin{tabular}{lll}
\hline No & Specification & Size $(\mathrm{mm})$ \\
\hline 1 & Length & 2494 \\
\hline 2 & Width & 1257 \\
\hline 3 & Height & 1082 \\
\hline
\end{tabular}

\subsection{Computational Domain}

Figure 5 illustrates the Computational Area of CFD aerodynamic analysis. (a) describes the dimensions of the computing region expressed in $\mathrm{L}$, where $\mathrm{L}$ is the length of the vehicle to be simulated, (b) describes the boundary condition (Franck, Gerardo and D'Elia, Jorge. 2004). The velocity inlet is included in speeds of $15 \mathrm{~km} / \mathrm{h}, 30 \mathrm{~km} / \mathrm{h}, 45 \mathrm{~km} / \mathrm{h}$ and $60 \mathrm{~km} / \mathrm{h}$, respectively. While pressure outlet input value 0 .

(a)

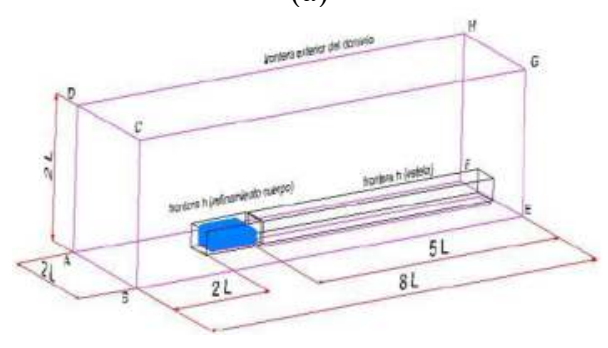

(b)

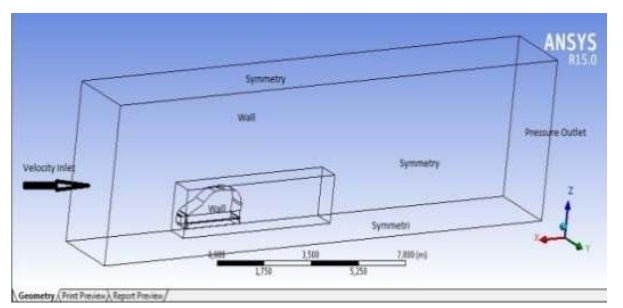

Fig. 5. (a) The size of the computing area. (b) description of boundary conditions in the computing area. 


\subsection{Meshing}

The mesh generation is done gradually that is making the mesh on the whole volume of wind tunnel that has been combined into volume with the car body. Next is to close the mesh on the wall of the car body and the road with the inflation of making a layer around the wall. Then create a new box geometry on the design modeller to make a more mesh process around the body of the car. The number of grids is 919,796 cells, and uses the tetrahedrans model. This is done to improve the accuracy of calculations on turbulent flow types.

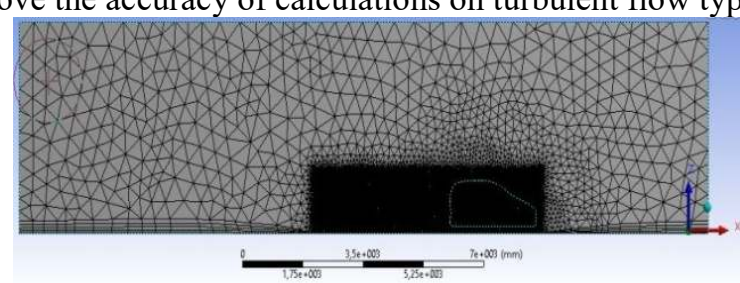

Fig. 6. Meshing whole.

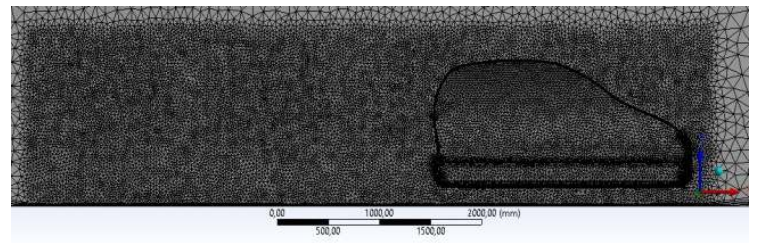

Fig. 7. Meshing on carbox geometry.

From the mesh generation process performed, the skewness value of 0.76 value is below 0.85 as the maximum limit specified Computational Fluid dynamics.

\subsection{Parameter simulation}

The method used using the parameters as follows:

Table 2. Parameter simulation on Urban Electric Car.

\begin{tabular}{|c|c|c|}
\hline No & Simulation Method & Information \\
\hline 1 & Solver & $\begin{array}{l}\text { Tipe: Preasure Based } \\
\text { Time: steady }\end{array}$ \\
\hline 2 & $\begin{array}{l}\text { Turbulance } \\
\text { Model }\end{array}$ & $\begin{array}{l}\text { k-epsilon realizable } \\
\text { standar wall functions }\end{array}$ \\
\hline 3 & Meterial & Air \\
\hline 4 & Solutions methods & $\begin{array}{l}\text { Gradient: Least Squares cell based } \\
\text { Pressure: Second order } \\
\text { Momentum: Second Order Upwind } \\
\text { Turbulance Kinetic Energy: Second Order } \\
\text { Upwind } \\
\text { Turbulannce Dissipation Rate: Second } \\
\text { Order Upwid }\end{array}$ \\
\hline
\end{tabular}




\section{Results And Discussion}

\subsection{Value of Drag Coefficient on Urban Electric Car}

Urban Electric Car design is expected to minimize obstacles or air pressure around the wall of the car. Because the greater the value of drag will directly affect the energy consumption of the car. Figure 8 shows the coefficient value of drag on Urban Electric Car at each speed.

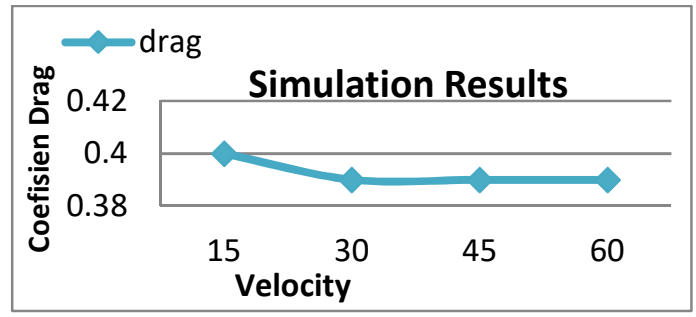

Fig. 8. Graph of Drag Coefficient on Urban Electric Car.

Based on Figure 8 the drag coefficient of urban electric car shows the same tendency value, between speed $15 \mathrm{~km} / \mathrm{h}, 30 \mathrm{~km} / \mathrm{h}, 45 \mathrm{~km} / \mathrm{h}$ and $60 \mathrm{~km} / \mathrm{h}$.

\subsection{Airflow occurring at the rate of Urban Electric Car at various speeds.}

Figure 9 illustrates the phenomenon of airflow occurring around the car. Visible picture (a) shows a very high air flow at the top of the car and the bottom of the car. While at the front and rear is the lowest flow. The body of the car that moves in the air cause aerodynamic style. The total force of the combined effect of the wall shear force (friction drag) and fluid pressure (pressure drag) will produce a drag coefficient. Figure (b) is a rear-view image. The flow of air through the car body will result in a pressure gradient between the front of the car and the back of the car, so that the fluid particles will experience a slowdown. This will cause the phenomenon of fluid flow separation (Fox, 2011). And the flow separation will cause the wake behind the car body that resulted in drag. The faster the occurrence of flow separation, wake will be wider so that the drag is getting bigger (Cengel, 2006).

The phenomenon of wake can be shown on the picture (c), while the display wake on the rear of the car is in figure (d). Figure (e) describes the turbulence phenomenon of a type of airflow in which fluid experiences irregular fluctuations. In turbulence flow the fluid velocity at a point changes in magnitude and direction. In the car industry, the form of car aerodynamics is an important parameter. Because the value of low kinetic energy turbulance represents better aerodynamic properties (Savli Matic, 2012). Figure (f) can be seen that the largest pressure distribution is on the front of the car body, which is the surface of the car body first passed the fluid flow. Then on the back of the car acquire a lower press from the front. This causes pressure drag. The greater the pressure drag the greater the drag coefficient value. The smaller the drag coefficient value that occurs in the car indicates that the design is already aerodynamic (Aljure D.E. et al, 2014). This impact on the savings of fuel usage. 

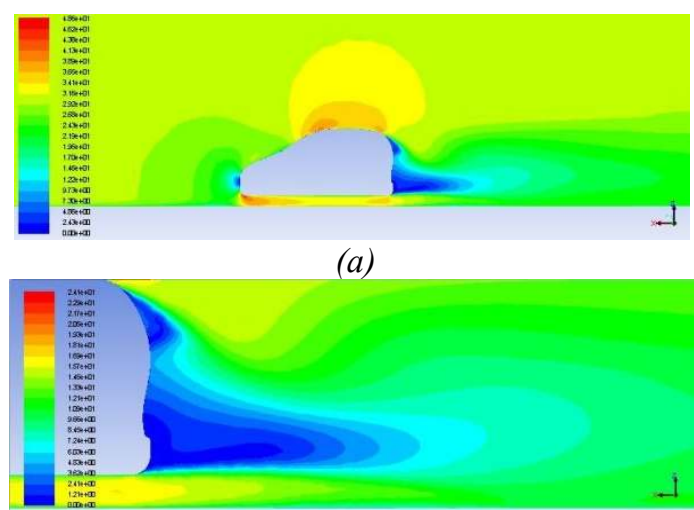

(b)

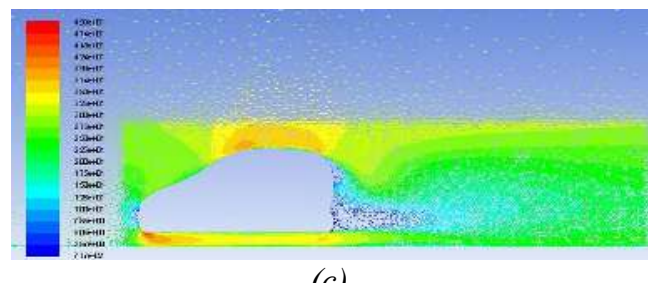

(c)

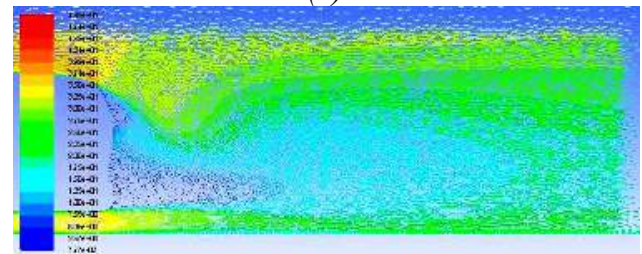

(d)

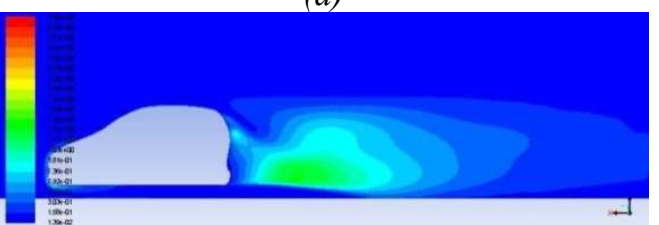

(e)

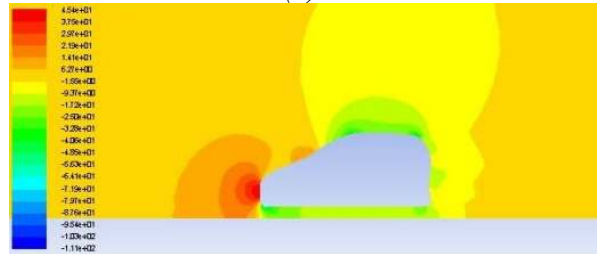

$(f)$

Figure 9 (a) Airflow phenomena occurring in the car body (b) Display of airflow phenomenon on the rear of the car (c) Wake on the car body (d) Display wake on the rear of the car (e) Turbulace phenomena on the car body (f) Contour pressure on the car body 


\section{Conclusion}

On the simulation that is done with various speed variations, the coefficient value of drag tends to be the same, that is 0,4 . With the result also produce picture of the same airflow display at each speed. In the future there is expected to study the urban electric car by modifying existing car body parts, such as making more streamline on the front, rounded corner on the car and add a spoiler on the back of the car.

\section{References}

[1] Aljure D.E. et al (2014) 'Flow And Turbulent Structures Around Simplified Car Models', Journal Computer And Fluids.

[2] Cengel, E. al. (2006) Fluid Mechanics: Fundamentals and Applications. New York: Mc Graw-Hill.

[3] Fox, W. E. al. (2011) Introduction to Fluid Mechanics, 6th edition. John Willey \& Sons Inc.

[4] Herminarto, E. al. (2004) 'Perancang Bodi Kendaraan, Sistem Perencanaan', Penyusunan Program Dan Penganggaran (SPS) jurusan pendidikan Teknik Otomotif.

[5] Jongebled, L. (2008) Numerical Study Using Fluent of The Separation and Reattachment Point For Backwards-Facing Step Flow, Mechanical Engineering, Resselaer Polytechnic Institute, New York.

[6] Savli Matic (2012) 'Turbulance Kinetic Energy. Universitas Ljubjana'.

[7] Thacher, A. E. al. (2012) 'Effecst of Suppressing the 3D Separation on the Rear Slant on The Flow Structures Around An Ahmed Body. University d'orleans.', Journal of Wind Engineering and Industrial Aerodynamic.

[8] Vino, G. E. al. (2005) 'Flow structures in the near-wake of the Ahmed model. Mechanical and Manufacturing Melbaourne.', Journal of Fluid and Structures. 